\title{
Boundaries and asymmetries in phonology and morphology: acoustic and phonetic analysis of vowel harmony in Brazilian Portuguese
}

\author{
Plínio A. Barbosa (PQ), Paula B. Papa (IC)
}

\begin{abstract}
This study aims to analyze two processes related to two asymmetries in Brazilian Portuguese: vowel harmony and reduction in pre-stressed vowels. For so, acoustic analyses were carried out couched in coarticulation theories and a corpus, containing test and control words of high and low familiarity, recorded with 10 subjects from São Paulo and Pernambuco states. Here, we present the first results of a paulista female subject for $\mathrm{F} 1$, which is a correlate of vowel height. We show that familiar words are more in harmony with the stressed vowels considering pre-stressed vowels / e a o/ indistinctly.
\end{abstract}

Key words: Vowel harmony, Acoustic Phonetics, Weakening processes.

\section{Introduction}

The process studied here is vowel harmony, a phenomenon in which vowels tend to modify their acoustic features to match with the stressed vowel, as in p[i]pino p[e]pino (cf Bisol, 1989) 1 . In this example it can be seen that pre-stressed vowel height changed to have the same height of the stressed vowel. That is why, the first formant (F1), an acoustic correlate of height, is examined here. When completed, this work will have analyzed ten individuals from two different dialects, allowing us to see dialectal differences and between-speaker variability. Both familiar and non-familiar words were used to examine the behavior of harmony in these two conditions. Here we present results from one female subject of São Paulo State for F1 and pre-stressed /e a o/. control words (same vowels in pre-stressed and stressed positions) are compared with test words were harmony is possible. Our hypotheses are that all vowel harmonize, and that harmony is more frequent in familiar words.

\section{Results and Discussion}

The results so far support the two hypotheses: /e/ and $/ 0 /$ lower before low stressed vowels and rise before high vowels, and /a/ raises in all cases. Harmony is more frequent in familiar words.
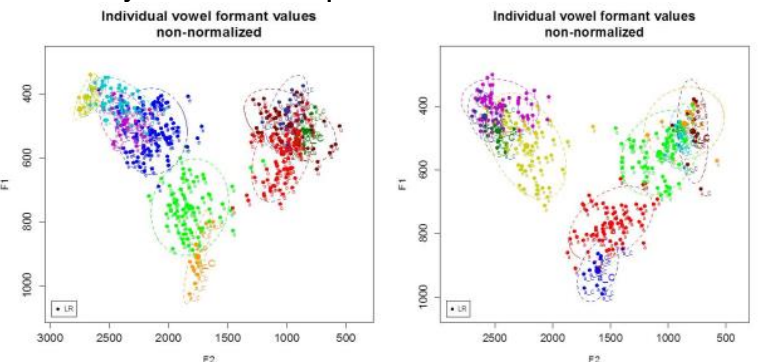

Image 1. Acoustic Space (test and control) of familiar (left) and non-familiar (right) words.
Chart 1. Results for $L R(F)$

\begin{tabular}{|c|c|c|c|c|c|c|}
\hline \multicolumn{7}{|c|}{ RESULT: IND. LR (F): F1 /el, /o/ and /a/ } \\
\hline $\begin{array}{c}\text { Median - F1 } \\
(\mathrm{Hz}) / \mathrm{e} /\end{array}$ & \multicolumn{6}{|c|}{ Familiar words } \\
\hline F1- Control & seg. /i/ & seg. /eh/ & seg. $/ a /=$ & seg. /oh/ & seg. $/ 0 /$ & seg. /u/ \\
\hline 496 & 438 & 529 & 602 & \begin{tabular}{|l|l|l}
544 \\
\end{tabular} & - & 500 \\
\hline $\begin{array}{c}\text { Median - F1 } \\
(\mathrm{Hz}) / \mathrm{e} /\end{array}$ & \multicolumn{6}{|c|}{ Non-familiar words } \\
\hline F1 - Control & seg. /i/ & seg. /eh/ & seg. $/ a /=$ & seg. /oh/ & seg. $/ 0 /$ & seg. /u/ \\
\hline 521 & 442 & 630 & - & 572 & - & 476 \\
\hline $\begin{array}{c}\text { Median - F1 } \\
(\mathrm{Hz}) / \mathrm{o} /\end{array}$ & \multicolumn{6}{|c|}{ Familiar words } \\
\hline F1- Control & seg. /i/ & seg. /eh/ & seg. $/ a /=$ & seg. /oh/ & seg. $/ \mathrm{e} /$ & seg. $/ \mathrm{u} /$ \\
\hline 532 & 529 & 651 & 657 & 610 & 552 & 529 \\
\hline $\begin{array}{c}\text { Median - F1 } \\
(\mathrm{Hz}) / \mathrm{o} /\end{array}$ & \multicolumn{6}{|c|}{ Non-familiar words } \\
\hline F1 - Control & seg. $/ \mathrm{i} /$ & seg. /eh/ & seg. $/ a /$ / & seg. /oh/ & seg. /e/ & seg. $/ \mathrm{u} /$ \\
\hline 563 & 485 & - & 639 & 557 & 542 & 510 \\
\hline $\begin{array}{c}\text { Median - F1 } \\
(\mathrm{Hz}) / \mathrm{a} /\end{array}$ & \multicolumn{6}{|c|}{ Familiar words } \\
\hline F1 - Control & seg. /i/ & seg. $/ e /$ & seg. /eht & seg. /oh/ & seg. $/ 0 /$ & seg. /u/ \\
\hline 844 & 769 & 658 & 798 & 747 & - & 717 \\
\hline $\begin{array}{c}\text { Median - F1 } \\
(\mathrm{Hz}) / \mathrm{a} /\end{array}$ & \multicolumn{6}{|c|}{ Non-familiar words } \\
\hline F1 - Control & seg. /i/ & seg. $/ \mathrm{e} /$ & seg. /ehts & seg. /oh/ & seg. $/ 0 /$ & seg. /u/ \\
\hline 803 & 763 & 723 & - & 824 & 767 & 736 \\
\hline
\end{tabular}

(corrected t-tests with alpha $=0.05$ with the $\mathrm{R}$ package).

\section{Conclusions}

The results supported the initial hypotheses about the vowel harmony behavior and its frequency more frequent in familiar words - at least for the three analyzed vowels in pre-stressed position. The acquired knowledge was significant, due to the work that this study asked for: recording, segmenting, analyzing both phonetically and statistically to verify scientific hypotheses in contemporary phonological theory.

\section{Acknowledgement}

To PIBIC/CNPq, to our colleague Cássia and the subjects that were recorded, our sincere acknowledgments.

\footnotetext{
${ }^{1}$ BISOL, Leda. 1989. Vowel harmony: a variable rule in Brazilian Portuguese. Language Variation and Change 1: 185-198.
} 